\title{
SCIENCE.
}

Editorial Committee : S. Newcomb, Mathematics; R. S. Woodward, Mechanics ; E. C. Pickering, Astronomy ; T. C. Mendenhald, Physics ; R. H. Thurston, Engineering ; Ira Remsen, Chemistry ;

JosePh Le Conte, Geology; W. M. Davis, Physiography; O. C. Marsh, Paleontology; W. K.

BRooKs, Invertebrate Zoölogy ; C. HART MERRIAM, Vertebrate Zoölogy ; N. L. BRITTON,

Botany ; Henry F. Osborn, General Biology ; H. P. Bowditch, Physiology ;

J. S. Billings, Hygiene ; J. McKeen Catreld, Psychology ;

Danied G. Brinton, J. W. Poweld, Anthropology.

FrIdAy, MAY 17, 1895.

\section{CONTENTS :}

The Ballistic Galvanometer and its use in Magnetic Measurements : THomas GRAY ...........533

The Scientific Method and Modern Intellectual Life: Conway MacMrllan.................537

The Liquefaction of Gases-A Controversy: JAMES

LEwIs Howe ........................542

Current Notes on Anthropology (VIII.): D. G.

BRINTON .........................544

James Edward Oliver: GEORGE BRUCE HALSTED. .544

James Dwight Dana ...................545

Correspondence $:$..................... 546

The Education of the Topographer: W. M. Davis. The Helmholtz Memorial : Hugo MÜNSTERBERG.

Scientific Literature $:-\ldots . \ldots \ldots \ldots \ldots \ldots . . . . .548$

Dana's Geology: JosepH LE CoNTE. Warming's Systematic Botany; Chambers' Story of the Stars: DAVID P. ToDD. Ballard's The World of Matter: WYATT W. RANDALL.

Notes and News ........................554

Societies and Academies : - ..............558 The Geological Society of Washington; The Entomological Society of Washington.

New Books ........................560

MSS. intended for publication and books, etc., intended for review should be sent to the responsible editor, Prof. J. McKeen Cattell, Garrison on Hudson, N. Y.

Subscriptionsand advertisements should be sent to ScIENCE, 41 N. Queen St., Lancaster, Pa., or 41 East 49th St., New York.

THE BALLISTIC GALVANOMETER AND ITS USE IN MAGNETIC MEASUREMENTS.

The ballistic galvanometer gives one of the most convenient and reliable means of measuring the total quantity of electricity conveyed through a circuit by a transient current when the conditions are such as to admit of its legitimate application. It is well known, however, to experienced ob- servers that in a large number of the common applications of the instrument the results are doubtful because the fundamental principle on which the calculations are based is not sufficiently attended to. The object of the present note is to direct more particular attention to the conditions under which accurate results may be obtained.

Most text-books on electrical measurements give formulæ for the calculation of the quantity of electricity required to produce a given deflection, or throw, of the galvanometer needle, and also indicate how the constant of the instrument may be determined, and how the damping effect of the air and of induced currents may be allowed for. The formulæ assume as fundamental that the duration of the flow is negligibly small in comparison with the time which the needle takes to reach its greatest deflection. This fundamental condition is of course implied in the name ballistic, but it does not seem, from the applications which we find continually made of the instrument, that the simple statement, as commonly given, is sufficiently explicit to prevent a vicious use of this method of experiment. For the measurement and the comparison of the capacities of condensers and similar purposes the ballistic galvanometer is generally reliable, providing the constant is properly determined and suitable appliances used for manipulation. In magnetic measurements, however, it not 
unfrequently happens that the duration of the current is much too great, and not only too great, but variable throughout the series of observations, the results of which are compared. The carelessness with which this method of experiment is recommended by authorities who ought to know better is astonishing. We find, for instance, in one of the most widely used text-books on the practical application of electricity the statement that to measure the total induction across the armature of a dynamo a few turns of wire may be wound round the section of commutation and connected in series with a ballistic galvanometer, and the throw of the needle, when the field circuit is closed or broken, will indicate the induction. For any ordinary galvanometer such statements are simply nonsense.

Let us take, for the purpose of illustration, the measurement of the magnetic quality of iron, according to Rowland's method, or some one of the modifications of it which have come into use. Here the specimen is a ring, which, in most of the recent determinations, is made up of wire or thin sheet iron. The ring is surrounded along its whole length by one or more magnetizing coils, and over a short length by a secondary or induction coil, included in the circuit of a ballistic galvanometer. The inductions produced by different magnetizing forces are then measured by observing the corresponding throws of the ballistic galvanometer needle. Various modes of operation are adopted, as, for instance, the magnetizing force is changed by successive steps from an extreme value in one direction to an equal extreme in the opposite direction, and then back by similar steps, thus passing the iron through a complete cycle of magnetization. The corresponding successive throws of the galvanometer needle are then taken to indicate the increased or diminished magnetic induction, due to the different changes of magnetizing force. In another method the magnetization is changed always from the extreme in one direction as the zero for each observation. The change of magnetization is in this case produced either by diminution, and, if necessary, reversal of the magnetizing force in one magnetizing coil, or by the use of a second coil and a current sent through it in such a direction as tends to reverse the original magnetization. The reverse half of the cycle is then obtained by passing the extreme current through the second coil, then slowly decreasing it to the required value, and afterwards suddenly breaking the circuit. The changes of induction are measured as before by the deflections of the ballistic galvanometer needle. Other methods might be mentioned, but these will serve for our present purpose.

In order to illustrate the variable conditions under which such experiments are made, the curves given in figures 1-4 have been drawn by an autographic recorder showing the actual character of the induced current which is sent through the galvanometer under different circumstances. In figure 1 the numbers $1,2,3,4,5,6$, give the curves of variation of current with time (the ordinate being current and the abscissæ time) for the following set of operations : Two magnetizing coils being placed on the iron a constant current was established in one of them ; next, for curve 1 , a small reverse current was sent through the other coil ; for curve 2, the second coil was closed across the battery and the battery cut out ; for curve 3 , the battery put in circuit and the current again established; for curve 4 , the current was increased by short circuiting part of the resistance in the circuit; for curve 5, the short circuit was taken off and the current reduced to the same valve as at the end of 3 ; for curve 6 , the coil was closed across the battery terminal and the battery taken out of circuit. 
Figure 2 shows the result of a similar series with the magnetizing force for curve 1 greater and the operations 2 and 3 of figure 1 omitted. Figure 3 illustrates the result when the whole of the reverse current was put on in operation 1 , and the curve 2 shows the effect of short circuiting the battery in the second circuit. Figure 4 is the same as figure 3 so far as the first operation is concerned, but in the operation which gave curve 2 the second magnetizing circuit was simply broken. The scales of these curves are arbitrary, but are the same complete break of the magnetizing coil circuit.

The fact that the time required to produce the change of magnetization is dependent on the amount of change shows that, unless the period of the galvanometer needle be so long that even the longest of these times is short in comparison, the measurements of the higher magnetizations will be more in error than the lower. The effect of this on the magnetization curve of iron is to render the steep parts of the curve less steep. The curves 1 and 2 of figure 4

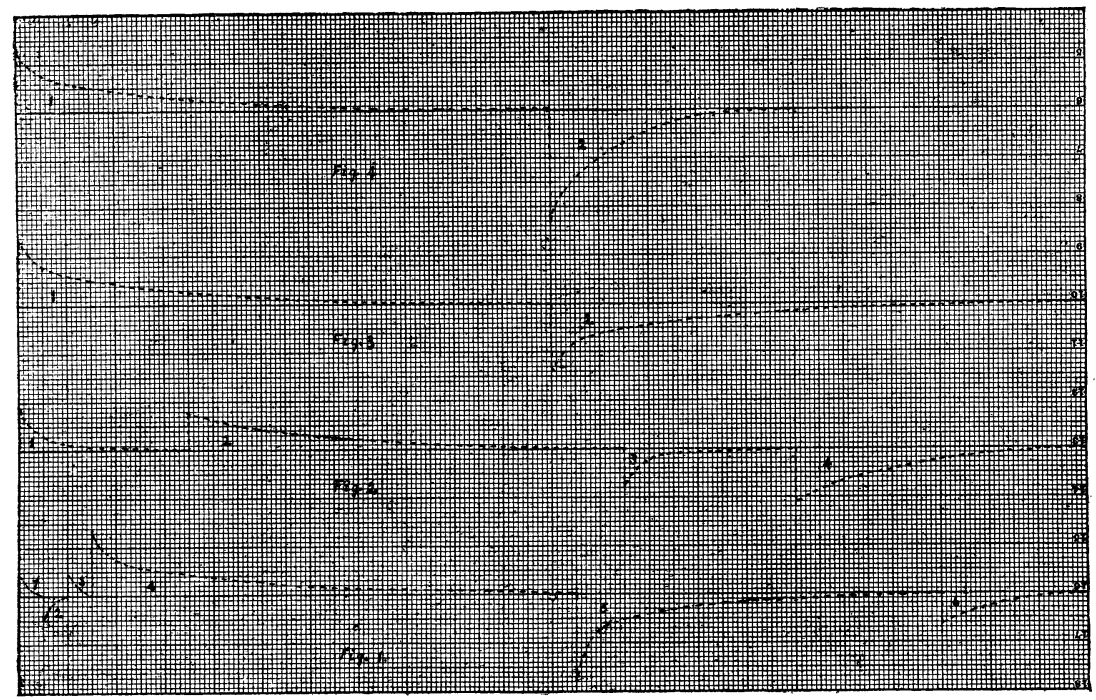

for the different curves, and hence the relative magnitudes of the changes of current may be estimated from the curves. The reverse current in the second coil was not at any time adjusted so as to give an equal but opposite magetization to that given by the coil through which the constant current was kept flowing. The two primary objects of drawing the curves were (a) to show the great difference in the time required to produce changes of magnetization as depending on the magnitude of the change, and (b) to show the differences in time for the two cases of short circuit and show the effect of the diminished inductive retardation when the circuit is broken in shortening the time required for the magnetization to change back as compared with the time required to produce it. Curve 2 of figure 3 compared with curve 2 of figure 4 shows the relative times when in the first case the e. m. f. is removed, but the circuit left closed and in the other case the circuit is broken. Comparisons between the deflection due to the application and the removal of magnetizing force should always be made in such a way that the circuit has the same inductive retardation in both cases. 
The e. m. f. should therefore be introduced and removed without breaking the circuit.

If we assume no damping action on the needle the equation to its motion is

$$
\frac{d^{2} \theta}{d t^{2}}+n^{2} \theta=\mathrm{x}
$$

where $n$ is a constant depending on the galvanometer and the intensity of the magnetic field at the needle, while $\mathrm{X}$ depends on the galvanometer and on the nature of the transient current. If we suppose the impulse given to the needle to be due to the charge or discharge of a magnetic field and take the permeability of the core as constant we may put $\mathrm{X}=\mathrm{A} \mathrm{e}^{\alpha \cdot t}$ where $\mathrm{A}$ is a constant depending on the galvanometer and $\alpha=\frac{\mathrm{R}}{\mathrm{L}}$ where $\mathrm{R}$ is the resistance and $\mathrm{L}$ the co-efficient of induction.

We thus get $\frac{d^{2} \theta}{d t^{2}}+n^{2} \theta=\mathrm{A} \mathrm{e}^{-\alpha t}$

The solution of this equation is

$$
\theta=\frac{\mathrm{A}}{n^{2}+a^{2}}\left\{\mathrm{e}^{-a t}+\frac{a}{n} \sin n t-\cos n t\right\}
$$

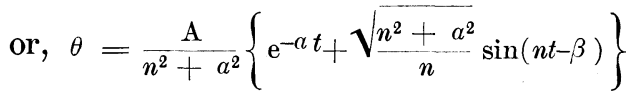

where term $\beta=\frac{n}{a}$

The constant $n$ is equal to $2 \pi / T$, where T is the free period of the needle.

Take, as a particular case, a ring of mean circumference $l=30$ centimetres, and cross sectional area $S=2$ square centimetres, and suppose the total number of turns on the magnetizing coil to be $\mathrm{N}=600$, the permeability $\mu=2000$, and the resistance 1 ohm. Then the increase or decrease of induction per unit current $\times \mathrm{N}=\mathrm{L}=$ ${ }_{1}^{4} \frac{\mathrm{N}^{2} \mu \mathrm{S}}{\times 10^{9}}=\frac{6}{\mathrm{r}^{6}}$ nearly in henrys. Hence we have $\alpha$ or $R / L=\frac{10}{6}$, and the current at time $t$, after the removal of the e. m. $f$., the circuit remaining closed, is $\mathrm{C}_{\mathrm{t}}=\mathrm{C}_{o} \mathrm{e}^{-\frac{10}{6}} t$ where $C_{0}$ is the current just before the e. m. f. is removed. Giving $t$ different val- ues in seconds we have the following values of the ratio $\mathrm{Ct}_{t} / \mathrm{Co}_{0}$ :

$\begin{array}{llllll}t \text { in seconds }=1 & 2 & 3 & 4 & 5\end{array}$ $\mathrm{C}_{\mathrm{t}} / \mathrm{C}_{\mathrm{o}}=0.18890 .035650 .00673 \quad 0.00127 \quad 0.00024$

If the resistance be taken equal to $10 \mathrm{ohms}$ then the unit of time in the above table is to be taken as one tenth of a second, and so on for different resistances. Precisely the same calculation applies to the case of increasing magnetization, only $\mathrm{C}_{0}$ is then the final steady current, and the numbers in the line $\mathrm{C}_{\mathrm{t}} / \mathrm{C}_{\mathrm{o}}$ are the differences from unity of the ratio $\mathrm{C}_{\mathrm{t}} / \mathrm{C}_{\infty}$, that is, the equation becomes $\mathrm{C}_{\mathrm{t}} / \mathrm{C}_{\mathrm{o}}=1-\mathrm{e}^{-\frac{10}{6}} t$.

Hence, remembering the high value which $\mathrm{L}$ may have at certain parts of the cycle in the case of iron, we see that to insure the whole quantity of electricity getting through the galvanometer coil in a small fraction of the quarter period the resistance would require to be in the neighborhood of 1000 ohms for a needle of 4 seconds period, and of 100 ohms for a needle of 40 seconds period.

The quantity of electricity which flows through the coil in time $t$ is given by the equation

$$
\mathrm{Q}=\int_{0}^{t} \mathrm{C}_{0} \mathrm{e}^{-\frac{\mathrm{R}}{\mathrm{L}} t}=\mathrm{C}_{0} \frac{\mathrm{L}}{\mathrm{R}}\left(1-\mathrm{e}^{-\frac{\mathrm{R}}{\mathrm{L}} t}\right)
$$

Hence in the case supposed above the quantity which flows in one second is about $\frac{4}{5}$ of the whole when the resistance is one ohm, and about $\frac{4}{5}$ of the whole in ${ }_{1 \frac{1}{0}}$ of a second when the resistance is $100 \mathrm{ohms}$.

The equatim $\theta \frac{\mathrm{A}}{n^{2}+a^{2}}\left\{\mathrm{e}^{-\alpha t}+\frac{\sqrt{n^{2}+a^{2}}}{n} \sin \right.$ $(n t-\beta)\}$ reduces to $\theta^{\prime}=\frac{\mathrm{A}}{a n}$ in the case of $\alpha$ being very great in comparison with $n$ and this form can be readily reduced to the equation commonly given on the supposition of the time of discharge being small in comparison with the period of the needle. Keeping to the case taken above of the 
period 4 seconds or quarter period 1 second we have the following values of $a$ :-

\begin{tabular}{|c|c|c|c|}
\hline$=$ & 1 & $10 / 6$ & 2 \\
\hline$\theta / \theta^{\prime}=$ & 0.632 & 0.774 & 0.810 \\
\hline
\end{tabular}

The middle one of these values corresponds to the ring discussed above when the resistance is one ohm. In these three cases the maximum deflection is reached after 1.54 seconds, 1.45 seconds and 1.40 seconds from the time when the e. $\mathrm{m}$. $\mathrm{f}$. is applied to or removed from the circuit. The conditions here taken may be considered extreme in so far as the period of the needle is concerned, but it is not difficult to find examples of actual measurements in which the period has been equally short.

The examples here given are probably sufficient to direct attention to the care that must be taken in the choice of apparatus and the arrangements of circuits when the ballistic galvanometer is used in magnetic measurements. The method is only applicable when $\alpha$ is so large that $\theta$ and $\theta^{\prime}$ are practically equal to each other and this condition is approximated to by making $\mathbf{R}$ large and $\mathrm{L}$ as small as possible. Hence, high e. m. f. s. should be used with high noninductive resistance in the circuit and magnetic force should be secured with small numbers of turns by using large currents. It is well always when comparing charge with discharge to keep the induction of the circuit the same in both cases by means of an apparatus which cuts out the battery and at the same time keeps the circuit closed through an equal resistance, instead of breaking the circuit when the discharge is measured. A check on the accuracy of the observations in any particular case may be obtained by observing the successive extreme deflection of the needle. If the first deflection has the proper magnitude the mean ordinate of the curves drawn through the extreme deflections to opposite sides of zero should be at all points zero. When the duration of the current is a large fraction of the time of swing of the needle the mean of the deflections to opposite sides will lie for the first few swings on the same side of zero as the initial deflection.

Thomas Gray.

Rose PoLytechnic Institute.

\section{THE SCIENTIFIC METHOD AND MODERN IN- TELLECTUAL LIFE.}

ScIEnce, as a necessary term, is possibly upon the verge of obsolescence. Within the last half-century it has spread the mantle of its meaning over almost every department of thought until to-day knowledge and science are perceived to be so nearly coextensive that the newer term might rightly yield to the priority of the older. While twenty-five years ago one heard much about science and the languages as rival claimants for place in the college curriculum, one now listens to the message of that useful science, classical philology. Then the polemic between science and religion seemed earnest indeed; now theologians and laymen are alike shocked when Mr. Benjamin Kidd suggests that there can not be a science of religion. Antithesis has softened into synonymy. It is not that the lion of science has devoured the lambs of art, literature and philosophy; it is rather that systematists of opinions and beliefs have determined a generic unity where before variety was supposed eternally to exist. Such condition has arisen, it may be presumed, from the prevalence at least among Western nations of what has come to be denominated the scientific method. This prevalence is not yet universality. It does not yet extend in full measure to every individual; nor does it, perhaps, persistently characterize the intellectual life of any man at the present time. The atavism of superstition must somewhere mar the image and superscription of one's intellectual inheritance. Nevertheless, so widespread and so dominant 